\title{
Acetazolamide Sodium
}

National Cancer Institute

\section{Source}

National Cancer Institute. Acetazolamide Sodium. NCI Thesaurus. Code C61622.

The sodium salt of acetazolamide, a nonbacteriostatic sulfonamide derivative with diuretic and anticonvulsant properties. Acetazolamide is a potent inhibitor of carbonic anhydrase that plays an important role in the control of fluid secretion. Inhibition of this enzyme in the kidney results in a reduction in the availability of hydrogen ions for active transport in the renal tubule lumen, thereby leading to increased bicarbonate and cation excretion, and increased urinary volume. Reduced bicarbonate level in circulation induces reduction of intraocular pressure via osmotic mechanism. The anticonvulsant activity of acetazolamide may contribute to inhibition of carbonic anhydrase in the CNS, which decreases carbon dioxide tension in the pulmonary alveoli, thus increasing arterial oxygen tension, 